\title{
Treatment of Gingival Recession Class II Defect using Buccal Fat Pad versus Platelet Rich Fibrin using Vestibular Incision Subperiosteal Tunnel Access Technique
}

\author{
Aya Kamal(D*, Ahmed Abdel Meguid Moustafa, Ahmed Abdallah Khalil \\ Department of Oral Diagnosis and Periodontology, Faculty of Dentistry, Minya University, Minya, Egypt
}

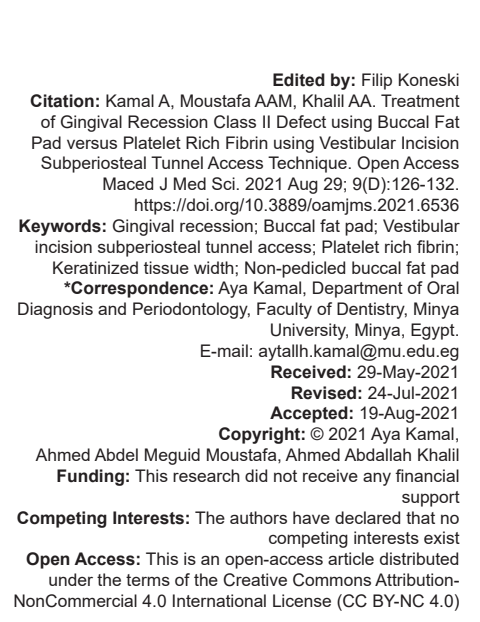

\section{Introduction}

Gingival recession (GR) is defined as apical migration of the gingival margin (GM) beyond the cementoenamel junction (CEJ) [1]. Treatment of isolated or multiple GR with different surgical procedures depends on many factors such as defect size, presence or absence of keratinized tissue adjacent to the defect, and thickness of the gingiva which are related to the defect and/or patient [2].

The treatment of recession defects associated with multiple teeth poses a greater challenge to the clinician as avascular root surface area is more extensive. Furthermore, thin biotype, decreased keratinized tissue width, root prominence, and root proximity make the choice of surgical treatment difficult as compared to localized GR type defects [3].

Different tunnel techniques that can maintain a better blood supply and maintain critical papillary integrity have been attempted for the management of recession defects. However, these procedures are technique sensitive, and tissue trauma to sulcular epithelium led to unfavorable healing outcomes as reported in some studies [4]. To avoid these complications in treatment procedures, the vestibular incision subperiosteal tunnel access (VISTA) approach was introduced.

The VISTA technology is invented by professor Zadeh combined with subepithelial connective tissue graft (SCTG) to treat GR. This is a minimally invasive modified coronally advanced subperiosteal tunnel technique [4].

The minimally invasive VISTA approach has several advantages for the successful treatment of multiple recession defects. The vertical incision that is given mesial to the defect reduces the possibility of traumatizing the gingiva of the teeth being treated. Furthermore, subperiosteal dissection reduces the tension of the GM during coronal advancement and maintaining blood supply to interdental papillae. In 
VISTA technique advancement of GM with augmented membrane or graft coronal to CEJ and securing the GM in a fixed stable position to prevent relapse in an earlier stage of healing gives better results in GR coverage [5].

Various adjunctive agents like recombinant human growth factors and platelet-rich plasma [6] have been used to accelerate healing and further enhance clinical outcomes. Platelet-rich fibrin (PRF), a secondgeneration platelet concentrate, is obtained from autologous blood with simplified processing without the need for biochemical blood handling [7]. It has become a focus of current studies because of its potential to accelerate healing. The processing of PRF involves the sequestration and concentration of platelets in autologous whole blood through centrifugation and natural polymerization [8].

Another adjunctive agent can be used such as buccal fat pad (BFP), which is a specially organized adipose tissue composed of a specialized type of fat termed syssarcosis, a fat that enhances intermuscular motion and is not subjected to lipolysis. Moreover, it has also been reported with minimal donor site morbidity and patient discomfort. The BFP has a rich plexus of blood vessels forming an internal microvascular network that ensures the survival of the flap after relocation with no need for anastomosis [9].

The use of nonpedicled BFP (NPBFP) for treatment of recession class I and II show an appropriate percentage of root coverage compared with sub-epithelial connective tissue graft which is the gold standard for treatment of recession after 6 months follow up period [10].

So in this study, it's proposed to evaluate the effectiveness of NPBFP versus PRF in the treatment of Miller Class II GR using VISTA technique.

\section{Patients and Methods}

This study was conducted on 40 patients with class II GR in the anterior or premolar segment. The entire patients were selected from the outpatient clinic of the Oral Medicine, Oral Diagnosis, and Periodontology Department. Faculty of Dentistry, Minya University.

\section{Ethical regulations}

The complete treatment plan was explained to all patients including detailed steps, risks, and expected results, and their full signed consent was obtained before entry into the study. The study complied with the rules set by the International Conference on Harmonization Good Clinical Practice Guidelines and the Declaration of Helsinki on the research ethics committee of the Faculty of Dentistry, Minya University (NO,320:Date, 18\2\2019).

\section{Patient selection}

Selected patients of both sexes are 20-55 years old, patients were systemically healthy based on questionnaire dental modification of Cornell index, O'Leary index (1972) was $<10 \%$ (the surgical therapy was not initiated until the patient reaches the $10 \%$ level or less of plaque accumulation), Buccal recession defects were classified as Miller Class II according to Miller's classification (1985), Clinical indication and/or patient request for recession coverage. On the other hand, Miller Class III or IV recession defects, pregnant females, Smokers, and patients with special needs or with any mental problems. All patients were using any kind of medications that could interfere with the healing of periodontal tissues. Such as chemotherapy and radiotherapy, Teeth with carious lesions, rotated and extruded teeth were excluded from the study.

\section{Randomization}

Forty patients with GR class II were divided into two groups, randomly selected for treatment with a coin toss:

Group I: (20 defects) NPBFP and Group II (20 defects) (PRF).

\section{Treatment plan}

Phase I therapy

Each patient was given detailed instruction on self-performed oral hygiene measures using a toothbrush and interdental brush or floss. Full mouth supra and subgingival scaling and root planning was performed on each patient in four sessions, one session for each quadrant, and was completed over 2 weeks. Local anesthesia was used for patient comfort if needed. Two weeks following the Phase I therapy, a re-evaluation was performed for each patient to confirm the suitability for the surgical phase.

\section{Surgical phase}

The operative site (Figure 1a) was anesthetized using $2 \%$ lignocaine $\mathrm{HCl}$ with adrenaline $(1: 2,00,000)$ using block or infiltration techniques according to premolar or anterior sites. The VISTA approach was begun with a vestibular access incision mesial to the defect, which provided access to the entire defect (Figure 1b)

A subperiosteal tunnel was created by passing the incision through the periosteum and inserting a 

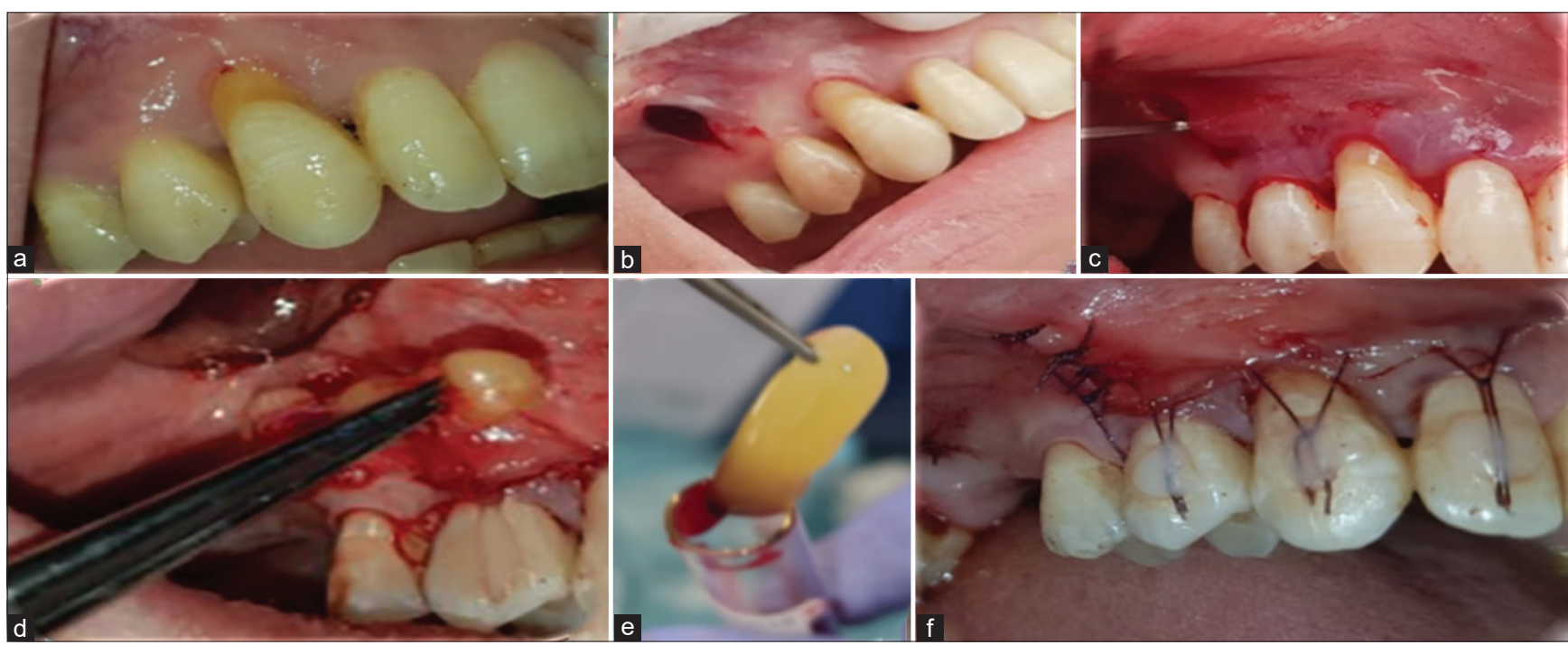

Figure 1: (a) Pre-operative view of the defect (b) Vertical releasing incision (c) Sub-periosteal tunnel was created to mobilize gingival margin and facilitate coronal repositioning (d) Application of buccal fat pad in the defect (e) Preparation of platelet-rich fibrin (f) Coronally advancement of the flap with suture and flowable composite

periosteal elevator between the periosteum and bone through the vestibular access incision. To mobilize GMs and facilitate coronal repositioning, the tunnel was extended at least one or two teeth beyond the teeth requiring root coverage. To achieve a low-tension coronal repositioning of the gingiva, the tunnel was sufficiently elevated beyond the mucogingival junction (MGJ) as well as through the gingival sulci of the teeth being augmented (Figure 1c).

Subperiosteal tunnel extension was carried out interproximally also below each papilla without making any surface incisions.



Figure 2: $(a+c)$ Before and after 6-month follow-up period in this case treated with vestibular incision subperiosteal tunnel access (VISTA) + platelet-rich fibrin $(b+d)$ Before and after 6-month follow-up period in this case treated with VISTA+buccal fat pad

The PRF membrane was prepared by taking $10 \mathrm{ml}$ of intravenous blood and centrifuged at 3000 RPM for $10 \mathrm{~min}$. After centrifugation, the PRF clot was removed from the tube with the help of tweezer and separated from the RBC base and transferred onto the gauze. The PRF obtained was formed of the membrane by squeezing out the fluid from the fibrin clot (Figure 1e). The PRF membrane was trimmed and adjusted to cover the root through the subperiosteal tunnel with fine-tipped curved serrated forceps. The membrane and mucogingival complex were to be then advanced coronally and stabilized in the new position with the help of suture and flowable composite (Figure 1f).

For the cases which were treated with NPBFP, before harvesting BFPG, a terminal infiltration anesthetic was injected into the region of the upper first and second molars at the intended BFPG recipient site. A horizontal incision measuring $1.5 \mathrm{~cm}$ was made at the bottom of the vestibule with a no.15 blade, in the region of the maxillary right or left first and second molars, depending on which side the surgery was performed. A curved hemostat was used to reposition temporarily the muscles at the relevant location, to expose the adipose tissue. Adipose tissue was then removed. The patient's cheek was then compressed to promote the closure of the edges of the wound and joining the tissue. The donor site was immediately sutured (Figure 1d).

The NPBFP was placed into the recipient site at the level of the CEJ and fixed by sutures over the graft with absorbable suture thread.

The flap was coronally positioned to cover the entire NPBFP using a suture and flowable composite. Suspensory and simple sutures were made in the releasing incisions (Figure 1f).

\section{Postsurgical phase}

Routine verbal and written postoperative instructions for periodontal surgery were given to all patients including ice compression on the surgical site during the first $4 \mathrm{~h}$, a liquid and/or soft food diet for 3 days, no brushing of the teeth in the surgical region. As with all surgical procedures, patients were informed to contact 
the therapist if any problems were developed during the postoperative period. Mouth rinsing with a mouthwash containing $0.12 \%$ chlorhexidine digluconate* for $1 \mathrm{~min}$ every $12 \mathrm{~h}$ for 14 days. The postoperative medications prescribed were (amoxicillin+ clavulanic acid $625 \mathrm{mg}$ for 8 days) ${ }^{* *}$ every $8 \mathrm{~h}$ or clindamycin $300 \mathrm{~g}$ every $8 \mathrm{~h}$ for 7 days for patients allergic to penicillin and (ibuprofen ${ }^{* * *} 600 \mathrm{mg}$ every $12 \mathrm{~h}$ for 5 days). The sutures were removed 14 days after surgery. After this period, the patients were instructed to brush their teeth gently, with a soft-bristled toothbrush. All patients participated in a monthly program of professional tooth cleaning and oral hygiene instruction, from the $30^{\text {th }}$ day to the $180^{\text {th }}$ day after the surgery.

\section{Assessment methods}

Follow-up visits were performed on all patients regularly at baseline (before surgery), 3, and 6 months (Figure 2). The measures of the clinical parameters were assessed by the following parameters Using UNC. 15 probe and recorded in $\mathrm{mm}$.

The clinical parameters evaluated were probing depth (PD) measured from the GM to the bottom of the gingival sulcus; GR, measured from the CEJ to the GM; clinical attachment level (CAL), measured from the CEJ to the bottom of the gingival sulcus; width of keratinized tissue (WKT), measured from the MGJ to the GM; and the thickness of keratinized tissue (TKT), measured with the periodontal probe placed perpendicularly along the tooth axis in the most central portion of the keratinized tissue, between the GM and the MGJ. Under local anesthesia, slight pressure was applied to the probe toward the adjacent hard tissue. The percentage of root coverage was calculated by the following formula:

\section{$\frac{\text { Postoperative GR - Preoperative GR (baseline) }}{\text { Preoperative GR (baseline) }} \times 100$}

\section{Statistical methods}

Data entry and analysis were recorded on an investigative report and transferred to an IBM card, using IBM pre with statistical program "Statistical Package for Social Sciences" "SPSS" (SPSS Inc., Chicago, IL and Systat, Richmond, CA) under windows Version 22 to perform the following statistical analysis: Graphics were done by Excel Microsoft office 2010. Data were graphically represented using Harvard Graphic Windows HGW program.

Student $t$-test was used to compare between means of two groups. Paired $t$-test was used to compare

\footnotetext{
* Antiseptol, Cairo pharmaceuticals and chemical industries Co.,Egypt

** Augmentin (Amoxicillin +clavulenic acid), GlaxoSmithKline, Egypt

*** $\quad$ Brufen ${ }^{\circledR}$, Abbott, Egypt
}

two means before and after treatment within each group. A statistically significant level was considered when the $p<0.05$.

\section{Results}

Forty patients aged between 21 years and 45 years were enrolled in the study, of which all patients participated in the study except ten patients in Group I was interrupted in the follow-up period (bad oral hygiene practicing habits) due to the spread of corona pandemic disease, which affects follow-up period. A total of forty GRs comprising 34 anterior teeth and six premolars were treated with VISTA technique either with BFP or PRF. Data were expressed as mean \pm standard deviation of the parameters evaluated. Comparisons were made with each group between the baseline and 6 months evaluations. The student paired t-test was used to compare intragroup and intergroup measurements at baseline and 6 months.

\section{In Group I (BFP) and in Group II (PRF)}

All clinical parameters were statistically significant. Mean \pm SD concerning $P D, C A L$, and RD was decreased from preoperative to 6 months postoperative period, while WKT and TKT were increased from preoperative to 6 months postoperative period in both groups.

In the comparison between the two groups after 6-month follow-up period, there was no statistically significant difference between the two groups in all clinical parameters although it was significantly decreased in PD in Group I in comparison to Group II, while significantly decrease in CAL and RD in Group II in comparison to Group I. Regarding WKT, it was significantly increased in Group II in comparison to the Group I, whereas in TKT, there was significantly increased in Group I in comparison to Group II (Table 1).

Table 1: Comparison of parameters 6-month postoperative between BFP and PRF groups

\begin{tabular}{|c|c|c|c|}
\hline \multirow{2}{*}{$\begin{array}{l}\text { Parameters } 6 \text { months } \\
\text { post-operative }\end{array}$} & Group I (BFP) n=20 & Group II (PRF) n= 20 & \multirow[t]{2}{*}{$p$-value } \\
\hline & Mean \pm SD & Mean \pm SD & \\
\hline PD & $1.70 \pm 0.57$ & $1.85 \pm 0.37$ & 0.3 \\
\hline CAL & $2.45 \pm 2.11$ & $1.25 \pm 1.97$ & 0.07 \\
\hline $\mathrm{RD}$ & $1.45 \pm 1.67$ & $0.80 \pm 1.28$ & 0.1 \\
\hline WKT & $5.20 \pm 0.89$ & $5.55 \pm 0.99$ & 0.2 \\
\hline TKT & $1.8 \pm 0.37$ & $1.77 \pm 0.25$ & 0.8 \\
\hline
\end{tabular}

Regarding the percentage of root coverage: there was a statistically significant difference between the two groups during the follow-up period while there was a significant increase in the percentage of root coverage after 3 and 6 months follow-up period in Group II in comparison to Group I (Table 2). 
Table 2: Comparison of percentage of root coverage 3 and 6 months post-operative between BFP and PRF groups

\begin{tabular}{|c|c|c|c|}
\hline \multirow{2}{*}{ Percentage of root coverage } & Group I (BFP) n=20 & Group II (PRF) n=20 & \multirow[t]{2}{*}{$p$-value } \\
\hline & Mean \pm SD & Mean \pm SD & \\
\hline 3 months post-operative & $50.0 \pm 36.01$ & $81.30 \pm 27.53$ & $0.004^{*}$ \\
\hline 6 months post-operative & $51.25 \pm 36.53$ & $82.00 \pm 30.22$ & $0.006^{*}$ \\
\hline
\end{tabular}

\section{Discussion}

GR is considered a major esthetic problem for many patients. A wide range of therapeutic alternatives exists for the treatment of isolated or multiple GRs [11].

The choice of the suitable treatment modalities depends on the gingival height, the WKT, level of alveolar bone and interdental papillae, gingival biotype, and other esthetic demands [12], [13].

The envelope or tunnel technique is considered a suitable treatment modality for multiple adjacent recessions [14]. However, the traditional tunnel technique was found to be sensitive and time consuming [15].

VISTA technique presents advantages over the traditional tunnel technique in the treatment of multiple GRs. It provides wider access to the entire surgical region and improves visualization through the single vestibular incision. Preservation of circulation in an apicocoronal direction is mandatory for treatment success. At the same time, vertical incision allows the detection of any tissue tags which will disrupt the continuity of the traditional tunnel technique [11], [16]

NPBFP was augmented with VISTA technique; success of cases of NPBFP has been attributed to the ease in harvesting the buccal fat graft through a fast surgical technique with low donor site morbidity and a low rate of complications [17]. The positive results are also attributed to the rich vascular supply that guarantees to maintain the vitality of the graft and the presence of stem cells that aid in tissue regeneration and differentiation of the grafted adipose tissue into the stratified squamous epithelium and dense connective tissue [18]. There is a report of long-term maintenance of the graft structure and volume since the BFP does not undergo lipolysis [19].

PRF was also used in the study as growth factors present in PRF play a vital role in hard- and soft-tissue repair. These growth factors include plateletderived growth factor, epidermal growth factor (EGF), transforming growth factor-beta (TGF- $\beta$ ), vascular EGF, insulin-like growth factor-1 [20].

Furthermore, these growth factors have been shown to accelerate bone repair and promote fibroblastic proliferation, increase tissue vascularization. Because PRF may enhance the healing of soft tissues as well as bone, its placement under coronally positioned flap in recession defects have been previously reported [21], [22].

Our results in the PRF group has approached the outcome achieved by Rutuja et al. [23], who found that the percentage of root coverage obtained at the 6 -month postoperative period was $83 \%$ with canine and $100 \%$ with lateral incisor which is class I GR after treatment with VISTA technique and PRF.

Another case series describes the use of (VISTA) technique in combination with PRF membrane and VISTA with CTG for treatment of GR defects. The results demonstrated $100 \%$ root coverage in all the cases at 6 months, respectively, in both treatment modalities [24] and this variation in the results may be related to the previously mentioned variation factors as well as the number of cases.

Another 12-month follow-up study evaluated the use of PRF in the treatment of multiple GRs with VISTA and found a significant improvement during the early periodontal healing phase with $96 \%$ root coverage [2].

A case series of multiple GR coverage treated with VISTA. Approach with or without PRF showed that patients having Class I recession defects showed almost complete root coverage with VISTA technique alone and reflected no added advantage of PRF membrane. However, patients with Class III recession defects treated with VISTA + PRF-membrane showed more reduction in recession depth and gain in CAL as compared to sites treated with VISTA only [25].

Our results in BFP approached the following study by Tatiana et al. [10], who analyzed the efficiency of NPBFP graft (BFPG) for the treatment of Miller Class I or II GRs and compare these results with those of SCTG, which is considered the gold standard. The clinical parameters were evaluated at baseline and 1 , 3 , and 6 months postoperatively.

None of the evaluated clinical parameters differed significantly between the groups. Six months after surgery, the mean percentages of root coverage were $67.5 \%$ and $87.5 \%$ in the BFPG and SCTG groups respectively. In both groups, complete root coverage was observed in $50 \%$ of cases 6 months after surgery. The results presented here indicate that the use of BFPG transplant has clinical similarities with SCTG and both may be considered as clinically successful methods for treating Miller Class I and II GRs.

El Haddad et al. [26] reported that coronally advancement flap with pedicled BFP grafting in a maxillary first molar with the buccal root surface almost completely exposed, presenting Grade III mobility and Class II furcation involvement. One month after treatment, there was an average gain of $8 \mathrm{~mm}$ in root coverage and gained keratinized tissues with the excellent matching of color and texture were observed.

In 2010, Kumari et al. [27] used the same technique to cover a Miller Class III defect in a maxillary 
right molar and obtained a $4 \mathrm{~mm}$ gain in the attachment level. Agarwal et al. [28] also applied the technique in a maxillary molar with class IV GR and obtained CAL and keratinized tissue gain.

Ercan et al. [17] described two clinical cases, where the first one showed a gain of $7 \mathrm{~mm}$ in the attachment level, reducing the GR to $4 \mathrm{~mm}$.

Panda et al. [29] performed a subepithelial graft using the pedicled BFP and buccal flap advancement for root coverage of a Miller Class III GR exhibiting a $7 \mathrm{~mm}$ attachment loss and obtained keratinized tissue gain - which was initially absent - in addition to a gain of $4 \mathrm{~mm}$ in the attachment level.

Owing to the lack of studies involving the VISTA technique with NBFP, it was not possible to compare the results from the BFP group with those of other studies. However, GRs treated through BFP exhibited improvement in all clinical parameters as those treated through the PRF group. Therefore, the use of BFP can be considered a predictable treatment option for Miller class II GRs as PRF.

\section{Conclusion}

Both PRF membrane and NPBFP are effective in the management of Class II GR defects using VISTA technique. PRF group has better results regarding the percentage of root coverage than NPBPF group after 3- and 6-month follow-up.

\section{References}

1. American Academy of Periodontology. Gingival recession. In Glossary of Periodontal Terms. $4^{\text {th }}$ ed., Vol. 44. Chicago, Illinois: American Academy of Periodontology; 2001

2. Chatterjee A, Sharma E, Gundanavar G, Subbaiah SK. Treatment of multiple gingival recessions with vista technique: A case series. J Indian Soc Periodontol. 2015;19(2):232-5. https://doi.org/10.4103/0972-124x.145836 PMid:26015680

3. American Academy of Periodontology. Position paper: Epidemiology of periodontal diseases. $\mathrm{J}$ periodontal. 1996;67(9):935-45. PMid:8884652

4. Zadeh $\mathrm{HH}$. Minimally invasive treatment of maxillary anterior gingival recession defects by vestibular incision subperiosteal tunnel access and platelet-derived growth factor-BB. Int $\mathrm{J}$ Periodontics Restorative Dent. 2011;31(6):653-60. https://doi. org/10.11607/prd.4313

PMid:22140667

5. Jamwal D, Waghmare P, Mali A, Mali R, Chaudhari A, Landge N. Vestibular incision subperiosteal tunnel access (VISTA) for root coverage with platelet-rich fibrin (PRF): A case report. Int $J$
Recent Sci Res. 2017;8(10):21081-3. https://doi.org/10.26226/ morressier.59492807d462b80296c9ec2f

6. Agarwal K, Chandra C, Agarwal K, Kumar N. Lateral sliding bridge flap technique along with platelet-rich fibrin and guided tissue regeneration for root coverage. J Indian Soc Periodontol. 2013;17(6):801-5. https://doi.org/10.4103/0972-124x.124525 PMid:24554895

7. Choukroun J, Diss A, Simonpieri A, Girard MO, Schoeffler C, Dohan SL, et al. Platelet-rich fibrin (PRF): A secondgeneration platelet concentrate, Part IV: Clinical effects on tissue healing. Oral Surg Oral Med Oral Pathol Oral Radiol Endod. 2006;101(3):e56-60. https://doi.org/10.1016/j. tripleo.2005.07.011

PMid:16504852

8. Anitua E. Plasma was rich in growth factors: Preliminary results of use in the preparation of future sites for implants. Int $\mathrm{J}$ Oral Maxillofac Implants. 1999;14(4):529-35.

PMid:10453668

9. Panda S, Del Fabbro M, Satpathy A, Das AC. Pedicled buccal fat pad graft for root coverage in severe gingival recession defect. J Indian Soc Periodontol. 2016;20(2):216-9. https://doi. org/10.4103/0972-124x.170844

PMid:27143839

10. Deliberador TM, Trevisani CT, Storrer CL, Santos FR, Zielak C, de Souza Filho CB, et al. Non-pedicled buccal fat pad grafts (NPBFP) to treatment for class I and II gingival recessions: Aclinical trial. Braz Dent J. 2015;26(6):572-9. https://doi. org/10.1590/0103-6440201300432 PMid:26963198

11. Rajeswari R, Kurmar TA, Gowda TM, Mehta DS, Kumar A. Management of multiple gingival recessions with the VISTA technique: An 18-month clinical case series. Int J Periodontics Restorative Dent. 2018;38(2):245-51. https://doi.org/10.11607/ prd.2990

PMid:29447318

12. Shkreta M, Atanasovska-Stojanovska A, Dollaku B Belazelkoska Z. Exploring the gingival recession surgical treatment modalities: A literature review. J Med Sci. 2018;6(4):698-708. https://doi.org/10.3889/oamjms.2018.185 PMid:29731944

13. Jasser AR, Alkudmani $\mathrm{H}$, Andreana $\mathrm{S}$. Platelet-rich fibrin as a new approach in treating gingival recession: Systematic review and meta-analysis. J Dent Oral Disord Ther. 2017;5(2):1-12. https://doi.org/10.15226/jdodt.2017.00173

14. Mormann W, Meier C, Firestone A. Gingival blood circulation after experimental wounds in man. J Clin Periodontol. 1979;6(6):417-24. https://doi.org/10.1111/j.1600-051x.1979. tb01940.x

PMid:295289

15. Zabalegui I, Sicilia A, Cambra J, Gil J, Sanz M. Treatment of multiple adjacent gingival recessions with the tunnel subepithelial connective tissue graft: A clinical report. Int J Periodont Rest Dent. 1999;19(2):199-206.

PMid: 10635186

16. Mahn DH. Treatment of gingival recession with a modified tunnel technique and an acellular dermal connective tissue allograft. Pract Proced Aesthet Dent. 2001;13(1):69-74. https:// doi.org/10.1111/j.1708-8240.2002.tb00143.x

PMid:11301532

17. Ercan E, Çandirli C, Uysal C, Uzun BC, Yenilmez E. Treatment of severe gingival recession using pedicled buccal fat pad: histological and clinical findings. Clin Exp Health Sci. 2016;6(4):191-4. https://doi.org/10.5152/ clinexphealthsci.2016.02

18. Farré-Guasch E, Martí-Pagè $C$, Hernádez-Alfaro $F$ 
Klein-Nuland J, Casals N. Buccal fat pad, an oral access source of human adipose stem cells with potential for osteochondral tissue engineering: An in vitro study. Tissue Eng C Methods. 2010;16(5):1083-94. https://doi.org/10.1089/ten.tec.2009.0487 PMid:20078198

19. Poeschl PW, Baumann A, Russmueller G, Poeschl E, Klug C, Ewers R. Closure of oroantral communications with Bichat's buccal fat pad. J Oral Maxillofac Surg. 2009;67(7):1460-6. https://doi.org/10.1016/j.joms.2009.03.049

PMid:19531418

20. Anitua E, Sanchez M, Orive G, Andia I. The potential impact of the preparation rich in growth factors (PRGF) in different medical fields. Biomaterials. 2007;28(31):4551-60. https://doi. org/10.1016/j.biomaterials.2007.06.037 PMid:17659771

21. Reddy S, Prasad MJ, Agnihotri J, Amudha D, Singh S, Krishnanand P. Management of multiple recession defects using modified coronally advanced flap alone or with PRF. Int J Health Sci Res. 2013;3():133-8.

22. Aroca S, Keglevich T, Barbieri B, Gera I, Etienne D. Clinical evaluation of a modified coronally advanced flap alone or in combination with a platelet-rich fibrin membrane for the treatment of adjacent multiple gingival recessions: A 6-month study. J Periodontol. 2009;80(2):244-52. https://doi.org/10.1902/ jop.2009.080253 PMid:19186964

23. Rutuja PK, Lisa C, Rakhewar PS, Tanvi HS. The vestibular incision subperiosteal tunnel access (VISTA) for treatment of maxillary anterior gingival recession defects a case report. Int J Health Sci Res. 2017;7(7):360-5.
24. Reddy S, Prasad MG, Bhowmik N, Singh S, Pandit HR, Vimal SK. Vestibular incision subperiosteal tunnel access (VISTA) with platelet-rich fibrin (PRF) and connective tissue graft (CTG) in the management of multiple gingival recession a case series. Int J Appl Dent Sci. 2016;2(4):34-7. https://doi. org/10.4103/jisp.jisp_291_20

25. Garg S, Arora SA, Chhina S, Singh P. Multiple gingival recession coverage treated with vestibular incision subperiosteal tunnel access approach with or without plateletrich fibrin. A case series. Contemp Clin Dent. 2017;8(3):464-8. https://doi.org/10.4103/ ccd.ccd_142_17

PMid:29042736

26. El Haddad AS, Razzak MY, El Shall M. Use of pedicled buccal fat pad in root coverage of severe gingival recession defect. J Periodontol. 2008;79(7):1271-9. https://doi.org/10.1902/ jop.2008.070176

PMid:18597611

27. Kumari BN, Thiagarajan R, Narayanan V, Devadoss P, Mammen B, Emmadi P. A new technique for root coverage using buccal fat pad a short case report. Quintessence Int. 2010C;41(7):547-9. PMid:20614040

28. Agarwal C, Gayathri GV, Mehta DS. An innovative technique for root coverage using pedicled buccal fat pad. Contemp Clin Dent. 2014;5(3):386-8. https://doi.org/10.4103/0976-237x.137963 PMid:25191079

29. Panda S, Fabrro MD, Satpathy A, Das AC. Pedicled buccal fat pad graft for root coverage in severe gingival recession defect. J Indian Soc Periodontol. 2016;20(2):216-9. https://doi. org/10.4103/0972-124x.170844

PMid:18597611 